\title{
ОСОБЕННОСТИ ПРИМЕНЕНИЯ ТЕХНОЛОГИИ ПРОЕКТНО-ИССЛЕДОВАТЕЛЬСКОЙ ДЕЯТЕЛЬНОСТИ НА УРОКАХ АНГЛИЙСКОГО ЯЗЫКА В СРЕДНЕЙ ШКОЛЕ
}

\section{FEATURES OF THE PROJECT-RESEARCH ACTIVITY OF STUDENTS OF SECONDARY SCHOOL AT FOREIGN LANGUAGE LESSONS}

I. Migdal

M. Surkova

Summary: This article describes the features of the implementation of design and research activities of secondary school students, features of the organization and use of this activity in English lessons, and also gives recommendations on the development of skills in design and research activities in English lessons in secondary school.

Keywords: project activity, research activity, design and research activity, theoretical research, organization features, usage features, skills formation, formation analysis, implementation results, development recommendations.
Мигдаль Ирина Юрьевна

к.филол наук, дочент, Государственный сочиальногуманитарный университет, г. Коломна iramigdal@rambler.ru

Суркова Марина Владимировна

Государственный социально-гуманитарный университет, г. Коломна marina.surkova.1996@mail.ru

Аннотация: В данной статье рассматриваются особенности реализации проектно-исследовательской деятельности обучающихся средней школы, особенности организации и использования данной деятельности на уроках английского языка, а также даны рекомендации по развитию навыков проектно-исследовательской деятельности на уроках английского языка в средней школе.

Ключевые слова: проектная деятельность, исследовательская деятельность, проектно-исследовательская деятельность, теоретические исследования, особенности организации, особенности использования, формирование умений и навыков, анализ сформированности, результаты внедрения, рекомендации по развитию.

ся средней школы, способы организации и использования данной деятельности на уроках английского языка, а также даны рекомендации по развитию навыков проектно-исследовательской деятельности в рамках школьного курса по иностранному языку. Научная новизна состоит в том, что в работе предложены варианты применения проектно-исследовательской технологии на уроках иностранного языка в средней школе, способы организации занятий, примеры заданий на развитие творческих способностей и критического мышления обучающихся. В результате исследование показывает, что данная технология дает серьезные преимущества, а именно, активную вовлеченность учащихся в процесс обучения, рост мотивации, эффективную организацию учебного пространства.

В центре нашего внимания процесс развития иноязычной коммуникативной деятельности обучающихся средней общеобразовательной школы как фактор формирования всесторонне развитой личности. [2]

Одним из важнейших аспектов языковой подготовки, во многом определяющей качественный уровень владения языком, становится обучение проектно-исследовательской деятельности, неразрывно связанной с развитием языковых, творческих, исследовательских способностей обучающихся. Основная функция про- 
ектно-исследовательской деятельности в современной школе сводится к ориентированию обучающегося к творческо-исследовательской деятельности, направленной на разрешение практико-ориентированного задания. [5]

Проектно-исследовательская деятельность успешно реализуется на уроках иностранного языка, поскольку способствует развитию коммуникативных навыков обучающихся, навыков критического и творческого мышления, навыков межличностного и межгруппового взаимодействия.

По мнению ведущих методистов, современное образование должно быть направлено на решение следующих задач:

1. необходимо уметь взвесить все факторы конкретной проблемы, сделать выводы, учитывая полученные знания, умения и навыки.

Чтобы данные качества сформировались, необходимо учесть следующие условия:

- отказ от традиционной системы образования в сторону задания ориентированного обучения и преподавания;

- широко использовать самоанализ как обучающимися, так и учителем;

- формировать умение высказывать свои собственные идеи и задавать интересующие вопросы;

- увеличить количество времени на самостоятельную работу обучающихся;

- изменить традиционную роль учителя и обучающегося на уроке.

2. развивать желание учиться на протяжении всей жизни, черпая новые знания, умения и навыки, применяя их к изменяющимся условиям среды.

Е.С. Полат утверждала, что, «решить эти задачи не представлялось возможным в силу отсутствия реальных условий для выполнения при традиционном подходе к образованию, традиционных средствах обучения, в большей степени ориентированных на классно-урочную систему занятий». [9]

Проблема выбора метода работы существовала перед педагогами на протяжении долгого времени. Но в современных условиях нам необходимы методы, позволяющие инновационно организовать процесс обучения, взаимоотношения между учителем и обучающимся. Обучающиеся сегодня по-другому смотрят на мир, решают поставленные задачи, а значит и роль учителя также должна быть иной. [1]

Отсюда возникают следующие вопросы:

1. Как правильно организовать обучение посредством желания обучающихся?

2. Как мотивировать обучающихся использовать лю- бознательность, интерес к развитию творческих способностей? [11]

По определению Матяша Н.В., являясь интегративным видом деятельности, проектная деятельность включает в себя элементы игровой, познавательной, ценностно-ориентационной, преобразовательной, учебной, коммуникативной и творческой деятельностей. [6]

Зимняя И.А., Шашенкова Е.А. определяют исследовательскую деятельность как специфическую человеческую деятельность, регулируемую сознанием и активностью личности. С их точки зрения, исследование всегда направлено на удовлетворение познавательных или интеллектуальных потребностей, а продуктом деятельности становятся новые знания. [10]

В рамках данных дефиниций, мы рассматриваем проектно-исследовательскую деятельность как деятельность, ориентированную на проектирование собственного исследования (выделение целей и задач, принципов отбора методик, планирование хода исследования, определение ожидаемых результатов, оценка реализуемости исследования, определение необходимых ресурсов), его реализацию и оценку полученных результатов.

Возросший интерес к проблеме развития самостоятельности обучающихся в образовательном процессе требует подробного анализа и различных путей повышения их познавательной активности и самостоятельности. Мы считаем возможным способствовать развитию познавательной самостоятельности обучающихся через проектно-исследовательскую деятельность, так как в таком типе обучении наиболее активно устанавливается ориентир на воспитание автономной творческой личности. [3]

Согласно ФГОС ООО, основная цель обучения иностранным языкам в средней школе - формирование иноязычной коммуникативной компетенции, что предполагает практическое владение иностранным языком и развитие умений критического и творческого мышления. Считаем, что метод исследовательских проектов может стать эффективным инструментом достижения данной цели совместно с такими инновационными методами, как обучение в сотрудничестве, дискуссии, ролевые игры проблемной направленности. [5]

Проектно-исследовательская деятельность предполагает:

- наличие проблем, которые требуют знаний из разных областей наук;

- практическую, теоретическую, а также познавательную значимость предполагаемых результатов исследования; 
- требование творческой и самостоятельной деятельности как отдельного обучающегося, так и группы обучающихся, но с промежуточным контролем учителя;

- написание плана выполнения проекта, алгоритма действий, которые могут в процессе выполнения изменяться;

- использование исследовательских методов, то есть определение проблемы и задач по её решению;

- отбор методов исследования, поиск информации, оформление результатов;

- презентация выполненного проекта, постановка интересующих вопросов, обсуждение результатов, выводы, извлечение практической значимости темы исследования.

Далее мы подробно остановимся на примерах заданий для применения проектно-исследовательской технологии на уроках иностранного языка в среднем звене.

Учитывая возможность вариативности типов заданий и их содержательной модификации в рамках проектно-исследовательской деятельности на иностранном языке, мы можем выделить следующие виды исследовательской деятельности на уроках английского языка:

\section{1. Практические мини - исследования}

Данные исследования направлены на изучение и обобщение фактов, содержащихся в разных источниках. Эти исследования не длительны по времени и их можно использовать как в урочной, так и во внеурочной деятельности. Приведём примеры некоторых мини исследований: «Рейтинг экстремальных видов спорта», «Моя школа», «Разработка маршрута по странам изучаемого языка», «Здоровый образ жизни».

\section{2. Исследовательские проекты}

Данные проекты более продолжительны по времени, и разумно использование их учителем во внеаудиторное время. Исследовательская деятельность направлена на реализацию личностного подхода в методике обучения. Она отличается особым характером выполнения заданий, являясь творческим и ориентированным на развитие личности обучаемого. поскольку данный вид деятельности создаёт позитивную атмосферу сотрудничества, партнёрства учителей и обучающихся.

В процессе защиты проекта предусмотрено обсуждение решений, дискуссии. Следовательно, от обучающихся требуется умение отстаивать свою точку зрения, развивать дискуссию, приходить к компромиссному решению, что является одним из важнейших навыков на современном рынке труда.

\section{3. Кейс-технологии}

Данная образовательная технология предполагает разрешение обучающимися конкретных проблемных ситуациях в результат активной познавательной деятельности. При работе обучающихся с использованием данного метода организуется дискуссия в группах, выбирается вариант решения, представляются результаты анализа, происходит общее обсуждение.

\section{4. ^абораторные работы}

Данный тип научно-исследовательских проектов предполагает проведение экспериментальной работы в классе в рамках разнообразной тематики (работа с интерактивной доской, тесты, кроссворды и т.д.).

Примером проекта на уроке английского языка может быть тема «Summer holiday in London», где можно провести лабораторную работу «Места, которые хочется посетить». Ребята получают задание создать небольшую презентацию на английском языке. Дополнительным плюсом является тот факт, что у обучающихся развиваются навыки не только исследовательской деятельности, но и также навыки работы с информационными технологиями и способности ориентироваться в виртуальном пространстве для поиска и отбора необходимой информации. Презентация должна содержать 5-6 слайдов с фотографиями достопримечательностей Лондона и их кратким описанием. При этом, обучающиеся демонстрируют автономию в выборе содержания и способах оформления презентации. [13]

Эффективность проектной работы зависит от множества факторов, которые должны отслеживаться учителем при планировании того или иного проекта. Учителю необходимо учесть следующие рекомендации:

1. необходимо грамотно управлять познавательной деятельностью ученика, то есть переходить с позиции носителя знаний на позицию организатора;

2. необходимо учитывать такие факторы мотивации обучающихся, как успешная коммуникация, взаимопонимание и положительное отношение к учебному предмету;

3. необходимо использовать групповые формы работы (парная, в малых и больших группах);

4. необходимо оказывать своевременную помощь обучающемуся с учётом результатов его самостоятельной деятельности;

5. необходимо организовывать ситуации успеха (предлагать задания, соответствующие уровню каждого обучающегося);

6. необходимо поддерживать положительную эмоциональную атмосферу учебного сотрудничества;

7. необходимо создавать условия для подведения итогов работы с учётом саморефлексии и само- 
оценки. [10]

Успешная организация процесса обучения проектноисследовательской деятельности на уроках иностранного языка в среднем звене основывается на следующих принципах:

1. Проектно-исследовательская деятельность - это деятельностный навык.

Проектно-исследовательская деятельность чрезвычайно активное занятие, для успешного осуществления которого необходимо внедрение разнообразных творческих заданий (понимать значения слов, воспринимать картинки, истолковывать факты, делать умозаключения, выражать согласие или несогласие). Отсутствие деятельностного подхода приводит поверхностному восприятию материала, а значит к его неэффективному усвоению.

2. Проектно-исследовательская деятельность - средство повышения мотивации обучающихся.

Отсутствие интереса к заданию, предлагаемому для исследования, ведёт к низкой активности обучающихся, поверхностному овладению предметом, формализму в представлении результатов проекта, а значит к минимальной пользе от учебного занятия. Однако, если привлечь внимание обучающихся к теме или заданию, то положительный результат гарантирован. [6]

3. Обратная реакция - эффективный механизм успешной проектно-исследовательской деятельности.

Необходимо формировать взаимопонимание между учителем и обучающимся через обязательное выражение отношения к самому заданию и к его содержанию. Учёт мнений школьников, их идей по решению проблемы, как основа проекта, становится важным фактором проектно-исследовательской деятельности.

4. Предвосхищение задания - фактор успеха проектно-исследовательской деятельности.

Активный процесс по осуществлению проектноисследовательской деятельности начинается на стадии формулировки задания. Успех проекта зависит от грамотной подачи материала и эффектной презентации результатов (заголовки, фотографии, картинки, схемы и другие средства визуализации).

5. Уровень сложности заданий - индикатор значимости проектно-исследовательской деятельности в учебном процессе.

Мы могли бы привести знаменитую строчку из монолога Гамлета «Быть или не быть» ('To be or not to be') и попросить обучающихся сказать, сколько раз в ней употреблён инфинитив. Можно попросить школьников расположить в алфавитном порядке названия блюд в меню. Несмотря на существующие доводы о пользу таких заданий, они не имеют практической значимости, а значит являются неэффективными. Скорее всего, нас заинтересует, что именно Гамлет имел в виду, и что представляют собой блюда в меню.

Отбор задания для проектно-исследовательской деятельности должен основываться на психофизиологических и интеллектуальных особенностях возраста обучающихся.

6. Максимальное использование возможности темы и задания - секрет успеха проектно-исследовательской деятельности.

Учителю необходимо прогнозировать возможности применения данного задания для обучающихся различного уровня, возможности адаптации и модификации темы в соответствии с их интересами, возможности дальнейшего использования материала в образовательном процессе. Таким образом, материал проекта станет не столько предметом изучения, но и средством актуализации учебного и языкового материала.

7. Самостоятельная работа обучающихся - важный фактор проектно-исследовательской деятельности.

На уроках по проектно-исследовательской деятельности учитель занимает консультирующую роль, не навязывая свои решения по данной проблеме. Задача учителя - это раскрыть внутренний потенциал каждого обучающегося, научить его работать самостоятельно или в команде, развить навыки критического мышления. Учитель разбирает тему и задание с обучающимися, дает подсказки в виде лексики и употребления грамматики, остальную часть исследования и дальнейшего представления проекта обучающиеся выполняют сами: либо на уроке, либо дома. Важно напомнить обучающимся том, что нет смысла искать готовое решение в сети Интернет, так как продуктивного результата от выполнения задания не будет.

8. Проектно-исследовательская деятельность - самостоятельная деятельность по поиску новых знаний.

Самостоятельный поиск решения - один из аспектов проектно-исследовательской деятельности. Это означает, что обучающийся или группа обучающихся, созданная учителем или произвольно, должны на основе источников, рекомендованных учителем, самостоятельно, без его помощи найти решение данного задания. Так как это проектная деятельность, то потом необходимо оригинально представить результаты своего исследования, опираясь на критерии, которые были выданы учителем. Важно помнить о том, что развитие критического мышления и нестандартный поиск решения проблемы состоит в самостоятельной работе обучающихся, иначе никакой пользы от заданий 
по проектно-исследовательской деятельности не будет. [6]

Часто у многих учителей возникает вопрос: как сделать уроки по проектно-исследовательской деятельности интересными и более эффективными? Мы привели несколько типов уроков в помощь учителям:

1. «Уголок исследователей». Если у вас есть возможность организовать в рамках своего учебного заведения такое место, где обучающиеся могут обсуждать темы исследований, различные проекты, делиться идеями, - это замечательно. Уголок исследователей должен быть комфортным и уютным местом, куда обучающимся хочется приходить, и где их не будут отвлекать.

2. Конкурсы проектов. Если дать обучающимся задачу, выполнение которой будет вознаграждено, их пыл может значительно усилиться. Давайте темы исследования и проекты, не всегда большие по объёму и требующие длительной подготовки. Обучающимся самим захочется участвовать в таких проектах, проявить себя и свои способности.

Проектно-исследовательская деятельность является одной из самых полезных и интересных в использовании на уроках английского языка. Она важна особенно в средней школе, когда происходит пик интеллектуального и эмоционально-оценочного развития обучающихся.

Основываясь на проделанном исследовании, мы сделали следующие выводы. Обучение иностранному языку в школе представляет собой организованный, управляемый процесс, в ходе которого в результате взаимодействия учителя и ученика осуществляется воспроизведение и усвоение определенного языкового опыта. Этот сложный процесс включает в себя не только отработку и развитие грамматики, лексики, фонетики, но и работу с текстами разной направленности.

Проектно-исследовательская деятельность является одним из важных средств получения информации обучающимися в ходе самостоятельного исследования. Главное назначение проектно-исследовательской деятельности сводится к тому, что задача обучающегося состоит в том, чтобы основная работа была направлена на проектирование исследования, его реализацию и анализ полученных результатов.

На среднем этапе обучения иностранному языку проектно-исследовательская деятельность способствует успешному овладению иностранным языком как видом речевой деятельности и повышению уровня языковой компетенции обучающихся, поскольку успешно формирует ситуацию успеха и повышает мотивацию школьников. [4]

На основе всего выше сказанного мы делаем вывод о том, что обучение проектно-исследовательской деятельности на уроках английского языка является одним их важнейших средств обучения. Учителю необходимо уделять особое внимание данному виду учебного процесса, подбору различных тем и заданий на основе возрастных особенностей и интересов обучающихся.

Таким образом, опыт применения проектно-исследовательской технологии позволяет определить следующие ее функции в области обучения английскому языку:

1. обновление и расширение объема учебных материалов посредством самостоятельной поисковой и познавательной деятельности, в ходе которой происходит углубление получаемых знаний при работе с аутентичными источниками;

2. повышение учебной автономии обучающихся как способа организации самостоятельной деятельности школьников;

3. развитие творческого мышления обучающихся на основе предоставления доступа к повышенным объемам информации.

Обучение проектно-исследовательской деятельности в средней школе является наиболее важным, т.к. именно в этот период закладываются основы использования иноязычных средств общения в повседневной деятельности. Во время выполнения заданий, защиты проекта обучающиеся овладевают техникой организации исследовательской работы, составления проекта, публичного выступления, обучаются использованию иноязычной лексики, знакомятся с культурными реалиями страны изучаемого языка.

При этом необходимо, чтобы занятия по проектноисследовательской деятельности носили систематический и системный характер, представляли собой поэтапную систему, где каждая новая стадия исследования осуществляется на новом, более совершенном уровне, но при этом опираясь на ранее усвоенные знания, умения и навыки, развивая их и формируя новые.

В заключение хотим отметить, что учителю важно уметь грамотно организовать работу на уроках по проектно-исследовательской деятельности, правильно мотивировать и направлять своих обучающихся для достижения отличных результатов. 


\section{ЛИТЕРАТУРА}

1. Белова Т.Г., Белов И.П. Исследовательская деятельность обучающихся как современная педагогическая проблема // Современные исследования социальных проблем, №3-2(59), 2016. с. 41-46

2. Брыкова 0.В., Громова Т.В. Проектная деятельность в учебном процессе. - Москва: Чистые пруды, 2006. 32 с.

3. Гальскова Н.Д. Современная методика обучения иностранным языкам, // Москва, 2000. 198 с.

4. Голуб Г.Б., Чуракова 0.В. Методические рекомендации «Метод проектов как технология формирования ключевых компетентностей учащихся». - Сама$\mathrm{pa}, 2003.246 \mathrm{C}$.

5. Гулиянц А.Б., Гулиянц С.Б., Дмитриева Е.И., Зотова Е.М. и др. Практическое руководство по проектной и исследовательской деятельности школьников в области иностранного языка: Учебно-методическое пособие. -М., АПКиППРО, 2011. 384 с.

6. Десяева Н.Д. Исследовательская деятельность педагога. - Академия, 2003. 124 с.

7. Палаева Л.И. Использование метода проектов на среднем этапе обучения иностранным языкам в общеобразовательной школе (на материале английского языка): дис. канд. пед. наук. - Москва, 2005. 239 с.

8. Пассов Е.И. Урок иностранного языка в средней школе. - М.: Просвещение, 1998. 222 с.

9. Полат Е.С., Бухаркина М.Ю. Современные педагогические и информационные технологии в системе образования: учеб. пособие для студентов высш. учеб. заведений. - М.: Издательский центр «Академия», 2007. 368 с.

10. Полат Е.С. Метод проектов на уроках иностранного языка // Иностранные языки в школе. - 2000. - № 2, 3. С.30-35.

11. Friend-Booth D. Project Work. -Oxford: Oxford University Press, 1986. 543p.

12. Haines S. Project: Material for Teachers. -Harlow: Longman, 1989. 212p.

13. Ribe R., Vidal N. Project Work. Step by Step. - Oxford: Heinemann, 1993. 456p.

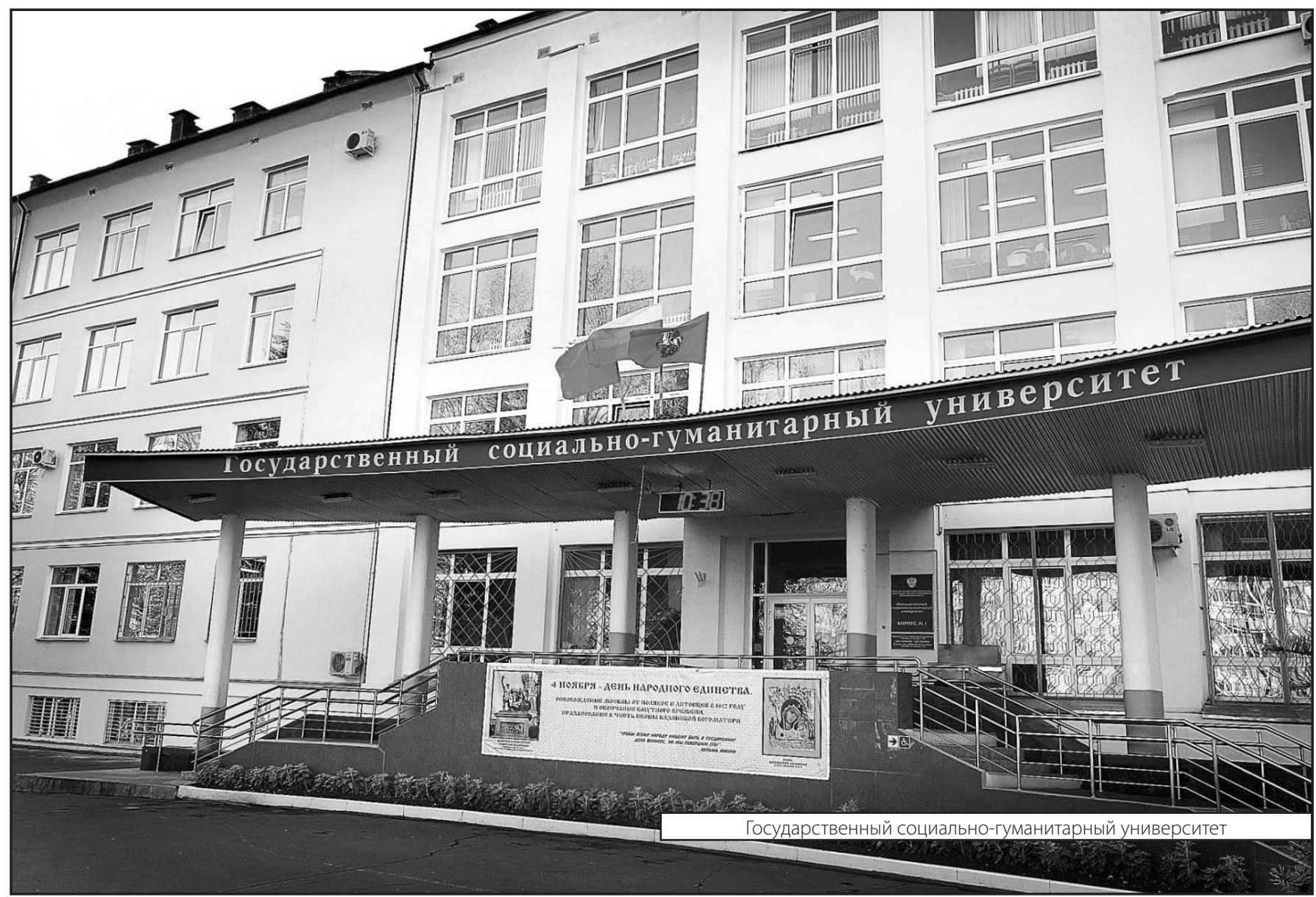

